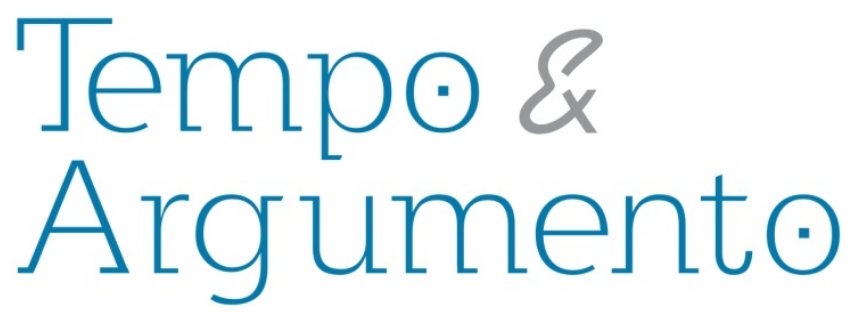

\title{
La última dictadura argentina en el centro de los debates y las tensiones historiográficas recientes
}

\begin{abstract}
Resumen
Este trabajo fue escrito para una mesa redonda sobre debates historiográficos en torno a las últimas dictaduras en el Cono Sur, y fue presentado en el marco del III Séminario Internacional Historia do Tempo Presente, organizado por la UDESC en octubre de 2017. El texto analiza los debates más recientes que han tenido lugar en el campo de la historia reciente sobre la última dictadura militar en la Argentina. Para ello se consideran tres temas que han sido objeto de polémicas: la manera de nombrar el crimen estatal; las formas de denominar el régimen autoritario de los años setenta, y una serie de discusiones más amplias sobre los juicios de lesa humanidad y el camino de la justicia que primó en el caso argentino. Si bien el objeto del análisis son los debates historiográficos de los últimos años, por la naturaleza de los temas en discusión, el análisis muestra como los campos político, jurídico, intelectual y académico se superponen, cruzan y tensionan mutuamente. Ello deja a la vista la alta politicidad del campo académico de la historia reciente y la autonomía relativa de los investigadores en relación con otras esferas de acción no académicas.
\end{abstract}

Palabras clave: Historia Reciente.

Historiografia. Dictadura. Derechos Humanos.

Justicia

\author{
Marina Franco \\ Doctora y magister en Historia por la \\ Universidad de Paris 7, Denis Diderot (Francia), \\ y doctora por la Universidad de Buenos Aires. \\ Docente e investigadora del IDAES. \\ Investigadora adjunta de CONICET. \\ ARGENTINA \\ marfrancomail@gmail.com
}

\section{Para citar este artículo:}

FRANCO, Marina. La última dictadura argentina en el centro de los debates y las tensiones historiográficas recientes. Tempo e Argumento, Florianópolis, v. 10, n. 23, p. 138 -166, jan./mar. 2018. 


\title{
The last Argentinian dictatorship at the center of recent historiographical debates and tensions
}

\begin{abstract}
This work was written for a round table on historiographical debates centering on recent dictatorships in the Southern Cone and was presented as part of the Second International Present-Day History Seminar, organized by the University of the State of Santa Catarina, Brazil (UDESC) in October of 2017. The work analyzes the most recent debates that have taken place within the field of recent history on the last military dictatorship in Argentina. The analysis takes into consideration three topics that have been controversial: the types of nomenclature used for state crime; the ways of naming the 1970 s authoritarian regime; and a series of broader discussions on court cases dealing with crimes against humanity, and path predominantly taken by the judiciary in the case of Argentina. Although the focus of the analysis is on historiographical debates of recent years, due to the nature of the topics under discussion, the analysis shows how political, judicial, intellectual and academic areas are superimposed, crosscut and influence each other. This makes clear the highly political nature of the academic field of recent history and the relative autonomy of researchers with respect to other, non-academic spheres of action.
\end{abstract}

Keywords: Recent History. Historiographie. Dictatorship. Human Rights. Justice.

\section{Introducción}

El propósito de este trabajo es presentar algunos de los ejes de discusión historiográfica de los últimos años en torno a la última dictadura argentina (1976-1983), así como las preguntas que ello plantea en relación con el funcionamiento del campo académico de la Historia reciente en ese país. La propuesta surgió de una invitación de los organizadores del II Séminario Internacional de Historia do Tempo Presente (UDESC, Florianópolis, 2017) con la intención de pensar las tensiones historiográficas en el Cono Sur latinoamericano en relación con las dictaduras. 
En la Argentina, desde su origen, el campo de la historia reciente -tal como se denomina allí lo que en otros países es historia del tiempo presente o historia del presente- se ha estructurado fundamentalmente en torno al problema de la última dictadura militar. Sin ninguna duda, puede decirse que esa historia -en su acepción como "terrorismo de estado"- ha sido el motor de surgimiento y dinamismo de esta especialización historiográfica. ${ }^{1}$ Lejos de cualquier proceso estrictamente académico, la centralidad y la evolución que el tema y las cuestiones asociadas -los derechos humanos, la memoria, la justicia, la experiencia revolucionaria de esas décadas- ha tenido en la historiografía argentina está en estrecha relación con el lugar que esas cuestiones tuvieron y siguen teniendo en el espacio público y político nacional.

En efecto, con el paso de los años, la dictadura, el terrorismo de estado y más ampliamente la década del setenta y la violencia política, siguen teniendo presencia constante en el debate público y se actualizan y resignifican en la medida en que el pasado sigue siendo objeto de movilización social, de políticas estatales -muchas veces opuestas entre sí- y objeto de conflictos y luchas en distintos escenarios -especialmente el judicial, pero también el político e intelectual-. En ese sentido, los debates historiográficos no pueden ser revisados de manera escindida de los debates públicos más amplios. ${ }^{2}$

Sin duda, esto último está relacionado con un elemento central de la historia reciente como campo historiográfico que es, en términos epistemológicos, la relación interdependiente entre pasado y presente o el hecho de que objeto y sujeto de investigación comparten un mismo tiempo histórico (MUDROVCIC, 2003; BÉDARIDA, 1997). Esta definición epistemológica puede ser expresada en términos aún más claros como la altísima politicidad de este campo profesional (PITTALUGA, 2016; FRANCO y

\footnotetext{
${ }^{1}$ Aunque en los últimos años la producción ha atravesado una saludable ampliación hacia otros problemas y períodos, tal como muestras las Jornadas de Trabajo de Historia Reciente que se realizan cada dos años en la Argentina desde 2003.

${ }^{2}$ Aquí solo analizaré las discusiones que han tenido respuestas y desarrollos historiográficos y académicos, dejando afuera otras polémicas igualmente interesantes pero que han tenido un desarrollo más político o mediático. Me refiero, por ejemplo, a la discusión sobre el número de desaparecidos y el cuestionamiento de la cifra histórica de los "treinta mil desaparecidos" (véase más adelante en este texto).
} 
LVOVICH, 2017), y esa particularidad se tensa especialmente en torno a ciertas cuestiones centrales de la historia nacional como es la última dictadura.

Los puntos de debate historiográfico que se analizarán a continuación están fuertemente concentrados en los años más recientes, periodo en el cual “los setenta” y la dictadura volvieron a estar en el centro de la escena política argentina. Ello se debe a varios factores que expondré sintéticamente para ofrecer un cuadro general que permita enmarcar las discusiones.

\section{Las circunstancias histórico-políticas (los años 2000 en adelante)}

En primer lugar, debemos considerar el espacio social creciente que la discusión sobre la dictadura y especialmente sobre la justicia (o su ausencia) fue readquiriendo desde mediados de los años noventa en la Argentina. En ese momento, la reacción social a la "impunidad" -como fue conocido el período marcado por las leyes y decretos que frenaron los juicios e indultaron a los militares entre 1986 y 1990³- comenzó a crecer como demanda social amplia, heterogénea y multisectorial. En segundo lugar, en ese mismo período y ligado a lo anterior, los procesos de elaboración social del pasado atravesaron un cambio importante con la aparición de una serie de memorias de la experiencia política revolucionaria de los años setenta (previos a la dictadura) que rehabilitaron una porción de la experiencia histórica que había quedado parcialmente silenciada por las políticas de la inmediata posdictadura. Por último, un poco después, el ciclo de gobiernos kirchneristas (2003-2015) colocó el “terrorismo de estado" y la década del setenta en el centro de sus políticas de gobierno. Esto se produjo en varios niveles distintos, por un lado, a partir de la coincidencia de una serie de decisiones judiciales, parlamentarias y del ejecutivo que reabrieron los procesos de justicia en relación con los crímenes dictatoriales; por el otro, a través de diversas políticas materiales y simbólicas centradas en el acercamiento con los organismos de derechos humanos, el desarrollo de agencias estatales y de políticas específicas de reparación, investigación y recuperación

\footnotetext{
3 Se trata de las leyes de Punto final (1986) y Obediencia Debida (1987), sancionadas durante el gobierno de Raúl Alfonsín y luego los indultos otorgados por decreto durante el gobierno de Carlos Menem en 1989 y 1990.
} 
de ese pasado, la construcción de sitios de memoria, el desarrollo de archivos, producción de contenidos escolares y mediáticos, etc. Por último, fue un elemento central también la construcción de una identidad política propia del kirchnerismo donde la experiencia de la militancia política de los años setenta y la represión sufrida fueron referencias centrales (MONTERO, 2011). ${ }^{4}$

Estos elementos contribuyeron para poner el pasado reciente, la represión y la violencia política, en el primer plano del debate político e intelectual en la década de los 2000. Esto no significa que antes de ese momento la dictadura no fuera objeto de atención, pero sin duda, la mayor parte de las discusiones -y su impacto en el campo de la historiografía- se produjeron en los últimos lustros. Ello se debe no sólo a esta repolitización general de ese pasado sino también a que, justamente en ese último periodo, puede hablarse de un espacio académico profesionalizado y consolidado en relación con el estudio del pasado reciente (FRANCO,LVOVICH , 2017).

A su vez, la coyuntura más específica del cambio de gobierno en diciembre de 2015 modificó nuevamente las relaciones de fuerzas y las legitimidades en torno al discurso sobre el pasado reciente. En efecto, el cierre del ciclo de gobiernos kirchneristas y la llegada al poder de una alianza de derecha y neoliberal, conducida por la fuerza “Cambiemos" y Mauricio Macri, ha producido nuevos realineamientos políticos y ha generado nuevas tensiones en los relatos sobre el pasado dictatorial y los años setenta, así como también significó un cambio en las políticas de derechos humanos sobre el pasado y sobre el presente. Así, por ejemplo, el cambio de signo político dio impulso y visibilidad a otras memorias y discursos que reactualizaron tópicos autoritarios que relativizan o minimizan la represión estatal de los años setenta. Algunas formas de ese cambio en el plano político discursivo ha sido la reaparición de la figura de la "guerra" para explicar lo sucedido durante la represión estatal; el cuestionamiento de la cifra histórica de "30 mil desaparecidos" acuñada por los organismos de derechos humanos como consigna política; y la exigencia de límites a los procesos de justicia actuales. Estos planteos -que no son nuevos pero que han resurgido con nueva legitimidad política-,

\footnotetext{
${ }^{4}$ Para una historia de la memoria en la Argentina y de los avatares de los procesos políticos en relación con la herencias dictatoriales, véase Lvovich, Bisquert, 2008 ; Crenzel, 2015.
} 

2017)).

Estas consideraciones histórico-políticas ofrecen el marco general para abordar y comprender algunos de los puntos de tensión que atravesaron el debate historiográfico sobre la última dictadura en la Argentina. Entre los temas que estuvieron presentes en la discusión académica de los últimos años abordaré tres de ellos: 1) la caracterización del crimen; 2) la caracterización de la dictadura en su conjunto, y 3) las políticas de derechos humanos, especialmente en relación con la justicia. Sin duda, hay otras discusiones que han generado importantes desarrollos historiográficos, en especial, el debate sobre la violencia revolucionaria, sus sentidos y responsabilidades, pero dado que no se centra directamente en la dictadura no lo tomaré como objeto de este trabajo. Sin embargo, como se verá, es un tema difícilmente separable de las otras cuestiones aquí analizadas. ${ }^{5}$

Por último, es necesario aclarar que personalmente he participado ampliamente de estas discusiones, de manera que mi posición será explícita en la mayoría de los casos. Por ello mismo, el propósito de este texto no es saldar los disensos en favor de unos u otros sino mostrar algunas de las maneras en que la historia reciente en la Argentina, como campo historiográfico, se relaciona con otras esferas como la política y la judicial. De esta forma, presentaré los debates de manera sintética para poder luego abrir una serie de interrogantes para pensar la práctica profesional y el campo de la historia reciente en general.

\section{La caracterización del crimen}

En la Argentina existe una discusión que en el ámbito académico se remonta por lo menos a comienzos de los años 2000 en relación a cuál es el concepto adecuado para

\footnotetext{
${ }^{5}$ La violencia insurreccional ha estado recurrentemente en discusión. En particular, fue importante el largo debate intelectual y político que surgió en la revista La Intemperie, en 2004, sobre los crímenes cometidos por las organizaciones revolucionarias y que fue luego publicado en dos tomos como "No Matar. Sobre la responsabilidad". (AAVV, 2007 y 2010).
} 
de intelección del mundo y el campo de los derechos humanos y su propia historia y luchas.

En efecto, históricamente, los organismos de derechos humanos recurrieron a la calificación de genocidio porque en la tarea de denuncia internacional permitía emparentar el caso con las grandes matanzas del siglo XX, especialmente con el Holocausto, la idea del terror estatal y la matanza de una población civil inerme (ALONSO, 2013). Sobre la década de los 2000 se levantaron algunas voces intelectuales para señalar que el concepto no era adecuado si se consideraban las características del crimen en la Argentina -motivado por razones políticas- y que el caso no entraba en la definición adoptada, con restricciones, en 1948 por la Convención para la Prevención y la Sanción del Delito de Genocidio de Naciones Unidas, que consideraba como genocidio los actos "cometidos con la intención de destruir total o parcialmente a un grupo nacional, étnico, racial o religioso". ${ }^{6}$ Poco después, se afirmó dentro de las ciencias sociales -a la par que en el seno de varios organismos de derechos humanos- una corriente de estudios sobre genocidio (genocide studies), encabezada en la Argentina por el sociólogo Daniel Feierstein, que retomaba y complejizaba este concepto para mostrar la pertinencia de su uso para el caso nacional (Feierstein, 2007). La aplicación académica provenía de una nueva modulación de la categoría, ahora denominada "práctica social genocida". Según su autor, el nuevo concepto permitiría tomar distancia de los límites de la figura estrictamente jurídico-penal y sostener que en el caso argentino el crimen se perpetró con la intención destruir "una parte sustancial" del "grupo nacional argentino" (FEIERSTEIN, 2007). Este ajuste conceptual facilita la inclusión de las víctimas de crímenes por motivos políticos, que estaban excluidas de la definición clásica adoptada por la

\footnotetext{
${ }^{6}$ Silvia Sigal planteó este argumento en el II Encuentro internacional sobre la construcción de la memoria Colectiva, organizado por la Comisión Provincial por la Memoria en agosto de 2001 y fue objeto de un intenso debate y reacción aireada del público (cfr. SIGAL, 2001; CUETO RÚA, 2016.) La definición original del jurista Raphael Lemkin incluía los grupos políticos pero estos fueron luego excluidos de la definición adoptada por la Convención por cuestiones de geopolítica internacional del momento (FEIERSTEIN, 2007).
} 
Holocausto nazi (FEIERSTEIN, 2007). ${ }^{7}$

Este planteo académico tomó forma en el momento en que se reactivaba el escenario internacional en relación con las violaciones a los derechos humanos en la Argentina a través de una serie de juicios en el exterior mientras dentro del país regían las Ilamadas "leyes de impunidad" que impedían juzgar esos delitos. Así, los fallos del juez Baltasar Garzón en España recurrieron justamente a la figura de genocidio para acusar y juzgar a militares argentinos, y luego también lo hicieron otros procesos legales dentro del país (FEIERSTEIN, 2007 y SCATIZZA, 2016). ${ }^{8}$ Esto tuvo impacto para reactivar el concepto como un objeto central de la reivindicación de los organismos de derechos humanos y adquirió un poder político movilizador ligado a las identidades y luchas de esos grupos (ALONSO, 2013). ${ }^{9}$

Sin embargo, en el ámbito historiográfico, la noción de genocidio ha sido, y sigue siendo, objeto de fuertes debates $\mathrm{y}$, en muchos casos, de rechazo. Las objeciones académicas se fundan en una serie de cuestiones que se cruzan de distintas maneras según los autores, que no necesariamente coinciden entre sí. Por un lado, se señala el

\footnotetext{
7 "Práctica social genocida" es definida como "aquella tecnología de poder cuyo objetivo radica en la destrucción de la relaciones sociales de autonomía y cooperación y de la identidad de una sociedad, por medio del aniquilamiento de una fracción relevante (sea por su número o por los efectos de sus prácticas) de dicha sociedad y del uso del terror, producto del aniquilamiento para el establecimiento de nuevas relaciones sociales y modelos identitarios" (FEIERSTEIN, 2007, p. 83). Para un detalle de las etapas generales y en el caso argentino, véase este mismo autor.

${ }^{8}$ Sin unanimidad, el concepto ha sido también objeto de polémicas en el ámbito de la justicia argentina por razones técnico-legales: rechazan su uso quienes sostienen que esa figura penal no permitiría la condena porque la Argentina está adherida constitucionalmente a los tratados internacionales sobre derechos humanos, entre ellos a la Convención de 1948 y el Estatuto de Roma de 1998 que excluye el genocidio por motivos políticos. Por ello, muchos magistrados sostienen que la categoría adecuada es la de crímenes de lesa humanidad (RAFECAS, 2011). En tanto, otros sostienen la validez legal de "genocidio" en el ámbito penal a través de la figura de "grupo nacional", efectivamente incluida en la Convención de 1948 (ROZANSKI, 2011). Estas diferencias se manifestaron por ejemplo, en la reciente sentencia de la llamada "megacausa" ESMA, en su tercer tramo, donde uno de los jueces votó en disidencia considerando que el delito debería ser considerado de "genocidio" -calificación que fue desestimada por sus pares- (Página 12, 3/12/2017, URL: https://www.pagina12.com.ar/8009o-hubo-unaindustrializacion-del-exterminio).

9 Para un análisis del proceso de surgimiento de la categoría entre el espacio judicial, el humanitario y el de las ciencias sociales, véase Alonso, 2013 y también Scatizza, 2016.
} 

masa uniforme (SIGAL, 2001; VEZZETTI, 2002; ROMERO, cit. en SCATIZZA, 2016). En consonancia con ello, algunos autores objetan que la amplitud de la noción de genocidio hace perder las especificidades y características que definen el caso argentino a fuerza de adecuar la evidencia empírica para hacerlo entrar en un modelo más general que incluye los grandes genocidios contemporáneos (SCATIZZA, 2016). En esa línea, se cuestiona el recurso al modelo de genocidio basado en etapas preconcebidas de desarrollo dentro de un esquema general como el que propone el sociólogo Daniel Feierstein (ALONSO, 2013; SCATIZZA, 2016).

Por último, desde otra óptica, se ha señalado el alcance más acotado del crimen en el caso argentino a partir de su dimensión selectiva y diferenciada (las víctimas elegidas), su número reducido (que no se ajustaría a las dimensiones masivas de un caso clásico de genocidio) y su duración temporalmente limitada (en cuanto fue un proceso de duración acotada) (VEZZETTI, 2014). Este mismo autor ha rechazado también el tipo de lectura binaria que induce la noción de genocidio, centrada en la oposición entre víctimas y victimarios, y especialmente enfocada en los segundos y sus tecnologías de exterminio, ya que ello no permitiría pensar los conflictos sociales amplios y previos que llevaron a ese exterminio, las responsabilidades y las actitudes de diversos grupos sociales y dirigencias que acompañaron y/o consintieron en diversos grados ese proceso criminal (VEZZETTI, 2014). En una variación de este argumento, pero en relación con los perpetradores, Scatizza sostiene que el concepto los unifica e iguala y, por ende, no permite pensar distintos grados de responsabilidad e intencionalidad entre unos y otros (SCATIZZA, 2016).

En todo caso, es evidente que la discusión sobre genocidio toca un punto fundamental de la interpretación de nuestro pasado reciente: el problema de cómo definir a las víctimas y las motivaciones contra ellas y, más ampliamente, cómo pensar el proceso y el conflicto político que está en la base del crimen estatal. La cuestión es clave porque si no se considera esa dimensión se obstruye la comprensión del proceso histórico 
que llevó al exterminio. En contraste, desde el campo de los derechos humanos o desde quienes defienden la noción de genocidio en las ciencias sociales, estos argumentos son percibidos como intentos de relativizar o minimizar la importancia del crimen, como ataques morales o políticos, y no cómo discusiones basadas en el esfuerzo de comprensión y conocimiento.

Muchos especialistas argentinos, desde diversas posiciones, tienden a defender otros conceptos menos encuadrados tales como masacre, terrorismo o terror de Estado o, retomando el concepto jurídico, crímenes de lesa humanidad. ${ }^{10}$ Más allá de que estos conceptos son de diferentes órdenes y definen objetos y problemas distintos que no siempre quedan claramente diferenciados (por ejemplo, el tipo de crimen, de régimen y de Estado), cada uno de ellos tiene algunas ventajas específicas y limitaciones importantes en relación con lo que permiten conceptualizar y sus supuestos. Ello está ligado a la dificultad más general del uso de los conceptos y al esfuerzo por encuadrar en términos únicos realidades complejas que tal vez se resistan a entrar en una única noción y requieran varias maneras de nombrar (ALONSO, 2013 y SCATIZZA, 2016). Así, por ejemplo, algunos autores prefieren la noción de crímenes de lesa humanidad, que se ha impuesto también en alineamiento con su uso judicial, mientras otros enfatizan que dicha noción afirma la dimensión del sujeto individual propia de una concepción liberal del derecho y desdibuja la intención del crimen dirigido al conjunto de la población (FEIERSTEIN, 2011). Otros, en cambio, consideran preferible la noción de terrorismo de Estado, o Estado terrorista, sistematizada por Eduardo L. Duhalde (1999), por su capacidad para definir las características y la centralidad que adquirió la violencia estatal en los años dictatoriales. A su vez, también se han señalado los límites de esta noción, por ejemplo, los sentidos del término "terrorismo"; el alcance de lo que el sintagma completo busca definir (un régimen, unos dispositivos represivos, ciertas formas de ejercicio del poder, un período, una subjetividades), y las maneras en que sobreentiende o simplifica la

\footnotetext{
${ }^{10}$ Masacre es la noción elegida por Vezzeti, 2002. Desde luego existe una amplia literatura que discute y objeta el concepto de genocidio en general, aquí nos atenemos a la discusión sobre la adecuación para el caso argentino. Para una discusión conceptual más amplia, véase, Gerlach, 2010. Este autor refuta el concepto de genocidio en favor de la noción de "violencia de masas".
} 
violencia estatal y la propia dictadura (PITTALUGA, 2010; FEIERSTEIN, 2011; ÁGUILA 2014; FRANCO en prensa (a)).

Si el problema de los conceptos es típico de las ciencias sociales y se pone en tensión en cualquier operación epistémica, en el campo de la historia reciente el problema de las formas de nombrar adquiere mayor tensión porque están en juego otras dimensiones y batallas, y así lo sienten parte de los actores concernidos. Claramente, una de las cuestiones centrales es el problema de la diferenciación y cruce (o no) de las esferas -la jurídica, la política, la humanitaria, la académica-, cada una con sus lógicas de intervención y acción distintas (o no, según lo asumen distintas posiciones). ¿Los investigadores trabajamos para buscar condena para los crímenes, para reparar a las víctimas, para comprender lo sucedido, para evitar que se repita, para pensar otras violencias actuales? ¿Qué motiva nuestro trabajo en este campo historiográfico? Las respuestas a estas preguntas construyen modos distintos de intervención y, desde luego, de conocimiento y conceptualización.

\section{La caracterización del régimen}

La explosión del campo de la historia reciente desde mediados de los años 2000 en la Argentina no supuso tanto una revisión de las líneas generales con que se había pensado la dictadura en los años ochenta (los estudios clásicos de la economía, la ciencia política y la sociología) como una sofisticación, complejización y diversificación de sus temas, enfoques y respuestas a los cómo y por qué de lo sucedido. En otros términos, se ha avanzado mucho en la comprensión y el conocimiento empírico del proceso, los actores y fenómenos asociados. Como parte de ello, de la profesionalización del campo y de la influencia de los estudios de memoria y de la historia oral, ha habido un movimiento disperso pero efectivo de revisión de conceptos, una reflexión sobre sus alcances y utilidades y un intento de tomar distancia analítica de las categorías y universos de los actores de la época. Estas motivaciones de índole científico-académica no sólo obedecieron a la sofisticación del conocimiento sobre el pasado, sino también a la necesidad de construir espacios de diferenciación y autonomía respecto de las luchas 
políticas -que los académicos en buena medida comparten-. Al mismo tiempo, tanto por el contexto político general de los años 2000 en adelante, como por la consolidación del campo historiográfico específico, se produjo un movimiento inverso: una fuerte interpenetración entre unas y otras esferas de acción, tal como muestra la discusión sobre genocidio.

En el marco de estos impulsos solo en apariencia contrapuestos (la profesionalización, por un lado, y la apropiación profesional de los combates públicos y políticos, por el otro), existe otro concepto que ha hecho el camino de la esfera política a la esfera académica. Se trata de la noción de dictadura cívico-militar, o en sus varias declinaciones posibles: dictadura militar-corporativa, dictadura cívico-militar-eclesiástica. Esta discusión ha estado presente en la última década en todos los países del Cono Sur, pero como en todos los casos, en el argentino también tiene sus motivaciones y lógicas específicamente nacionales. ${ }^{11}$

La noción de "dictadura militar" como definición del régimen se impuso casi sin matices de manera contemporánea al fenómeno, tanto en las ciencias sociales como en la esfera política -además de que se insertaba en una tradición de golpes de estado militares que en la Argentina tornaba natural esa denominación-. ${ }^{12}$ Sin embargo, en los años 2000, como parte de la reactivación política de la memoria de los años setenta y del terrorismo de Estado (por parte de las gestiones kirchneristas y desde la esfera política y periodística cercana al oficialismo y a los derechos humanos), comenzó a afirmarse la noción de "dictadura cívico-militar".13 El concepto tiene la intención de enfatizar la participación, complicidad y/o apoyo -según los casos- de los sectores civiles que formaron parte del bloque de poder detrás del golpe de estado y del régimen, en especial los sectores dominantes del poder económico.

\footnotetext{
${ }^{11}$ Para Brasil, entre otros Aarão Reis, 2014; Martins Filho, 2014; Fico, 2017; Demasi et al, 2010; y algunas consideraciones en Valdivia Ortiz de Zarate, 2003, para el caso de Chile.

${ }^{12}$ Ese uso convivía con formulaciones que daban cuenta de la participación y complicidad de diversos actores civiles, tema que si bien tenía menor peso público nunca estuvo enteramente ausente y fue parte de las primeras interpretaciones políticas y académicas del golpe de Estado y la dictadura en los años setenta y ochenta (MONTERO, 2016; COPELLO, 2017).

${ }^{13}$ Sobre su construcción como objeto discursivo y cristalización entre actores del gobierno en la década del 2000 y sus vectores dentro del periodismo, Montero, 2016.
} 
Este desplazamiento conceptual tuvo varias razones de coyuntura en la esfera política argentina. Por un lado, su proceso de activación se produjo a fines de los 2000 ligado a los combates políticos inmediatos del presente. En efecto, la emergencia del concepto se produjo en el contexto del fortísimo conflicto público que el poder ejecutivo -a cargo de Cristina Fernández de Kirchner- mantuvo con diversos grupos dominantes y, en particular, con algunos sectores económicos centrales de la escena política argentina a partir de 2008: el conglomerado de empresas lideradas por el grupo económico del diario Clarín y los sectores de los grandes productores rurales en conflicto por las políticas gubernamentales de retenciones a las exportaciones. Desde el oficialismo, el conflicto con estos grupos fue construido a partir de un discurso de asociaba el pasado prodictatorial de Clarín y de los grandes productores rurales y su condición de "cómplices" del terrorismo de Estado con su posición presente de enfrentamiento con el gobierno. ${ }^{14}$ En ese contexto, la emergente noción de dictadura cívico-militar venía a reponer algo silenciado -la participación y apoyo de esos grupos a la dictadura- a la vez que los deslegitimaba en sus posiciones presentes.

Por otro lado, un segundo factor ligado al anterior tiene que ver con el crecimiento de toda una línea de intervención política y judicial de los últimos años dirigida a investigar responsabilidades civiles en la represión y la asociación entre grandes intereses económicos y políticos durante el régimen dictatorial en favor de los sectores patronales, empresarios y/o concentrados de la economía. Así, se desarrollaron áreas de investigación donde convergieron actores y lógicas académicas, políticas y judiciales para estudiar las actuaciones de sectores civiles dentro o fuera del Estado, especialmente empresarios, financistas, actores eclesiásticos, medios de prensa y jueces. ${ }^{15} \mathrm{El}$ descubrimiento de esa trama de relaciones entre civiles y militares -leída en términos de complicidades, colaboraciones, omisiones, adaptaciones y/o directa autoría civil de

\footnotetext{
${ }^{14}$ Véanse ejemplos del discurso oficial al respecto en Montero, 2016. En contraste con esta discusión, varios trabajos académicos han complejizado el tema mostrando como el diario Clarín acompañó el golpe de Estado y la primera parte del régimen, pero rápidamente se transformó en un activo opositor en cuestiones como la política económica y en los últimos años, sobre la represión (Véase BORRELLI, 2016; ITURRALDE, 2016).

${ }^{15}$ Especialmente, la importante investigación sobre complicidad empresarial (AAVV, 2015). En el contexto de la reapertura de los juicios por crímenes de lesa humanidad se desarrolló toda una línea de investigación vinculada a la "responsabilidad civil" que permitió el juzgamiento y, en muchos casos, la condena de jueces, empresarios, sacerdotes y médicos por su actuación durante la dictadura.
} 
cívico-militar.

En todo caso, el término se expandió rápidamente en ese espacio público poroso conformado por las voces del oficialismo kirchnerista, los organismos de derechos humanos cercanos y amplios sectores políticos movilizados en torno al tema dictatorial. ${ }^{16}$ Casi simultáneamente, ingresó al campo de las ciencias sociales y se instaló con fuerza, no sólo por el contexto político descripto sino porque allí fue activado por una serie de actores que funcionaron de bisagra entre las esferas política, de los derechos humanos y la académica, entre ellos, especialmente el periodista Horacio Verbitsky y el Centro de Estudios Legales y Sociales (CELS). ${ }^{17}$ Fuertemente activado por estos actores, y en consonancia con el avance judicial, se desarrollaron entonces una serie de estudios que cruzaban transversalmente el espacio académico y el activismo de los derechos humanos, dedicados a mostrar las diversas formas de responsabilidad de distintos actores civiles y a repensar la trama entre lo público y lo privado durante la dictadura (especialmente, VERBITSKY,BOHOSLAVSKY, 2013; NÁPOLI et al, 2014; BOHOSLAVSKY, 2015 ; AAVV, 2015). Estos trabajos fueron claves porque abrieron toda una línea de indagación académica sobre el tema y fueron la base empírica para fundamentar la categoría de dictadura cívico-militar -o alguna de sus variantes- dentro del campo historiográfico. ${ }^{18}$

En efecto, la tracción de la esfera política y judicial sobre el campo académico fue casi automática. La categoría de dictadura cívico-militar se difundió y adaptó en las ciencias sociales sin procesos de revisión o discusión sobre sus alcances conceptuales y políticos. Sin duda, es el ejemplo más claro de la permeabilidad de esferas en el quehacer de la historia reciente en la Argentina, especialmente en la última década.

\footnotetext{
${ }^{16}$ El concepto ha tenido posteriores derivas políticas, por ejemplo la legislatura de la provincia de Buenos Aires por iniciativa opositora votó una ley que establecía su uso obligatorio en la documentación oficial, así como la cifra de 30 mil desaparecidos (Ley 14.910, 19/5/2017).

${ }^{17}$ Verbitsky reconoció ser uno de los impulsores del concepto (MONTERO 2016).

18 El trabajo de Bruno Nápoli, Celeste Perosino y Walter Bosisio (2014), por ejemplo, propone más específicamente la categoría de dictadura militar corporativa, o corporativa concentrada, en un esfuerzo de pensar más finamente el problema conceptual.
} 
Desde la investigación académica sobre la dictadura, ha habido intentos -en los cuales yo misma he participado- de discutir el concepto replantando sus presupuestos teórico-conceptuales (qué significa cívico, qué designa, qué permite explicar y qué no), sus presupuestos empíricos (el funcionamiento efectivo del régimen, su evolución, el peso y relación entre los distintos sectores y actores) y sus bases interpretativas y analíticas (el problema de la autonomía de la política, y la primacía entre las dimensiones política y económica para explicar el golpe y el régimen). Desde una perspectiva crítica, estas posiciones señalan que, sin duda, el énfasis en la dimensión militar de la dictadura es insuficiente para dar cuenta del fenómeno histórico y que es necesaria la investigación y conocimiento sobe la participación y responsabilidad civil en diversos grados y formas. Sin embargo, objetan el nuevo concepto porque sostienen que las características del régimen estuvieron dadas por la primacía del actor militar sobre los grupos civiles y no puede considerarse que fuera un gobierno compartido (ALEGRE, 2015; FRANCO, 2016a). A su vez, señalan que el régimen se definió y caracterizó por el intento de construir un proyecto político amplio que sobrepasaba en mucho la imposición de un proyecto económico de origen civil, tal como a veces es entendida la dictadura (CANELO, 2008 y 2016; FRANCO, 2016a). Por último, diversas voces también señalan el problema de la no diferenciación entre distintos tipos de responsabilidad y los deslizamientos entre las categorías legales y las del registro analítico de las ciencias sociales (por ejemplo, los usos poco definidos de las nociones de complacencia, adaptación, complicidad, responsabilidad, culpabilidad), pues ello oblitera la tarea de comprensión y conocimiento de lo que fue la dictadura, sus apoyos civiles y su dimensión política (VEZZETTI, 2014; ALEGRE, 2015; MONTERO, 2016; FRANCO, en prensa (b)).

En síntesis, en este caso, los argumentos críticos se centran tanto en los límites de los conceptos y su capacidad explicativa como en las interpretaciones globales sobre lo que significó la dictadura. Esta discusión muestra sin mediaciones el peso del presente en la construcción del pasado, siempre abierto y sujeto a ser reelaborado. En definitiva, una vez más, desnuda que toda historiografía es historia del presente. Si ello es así, ¿cuáles son nuestros controles epistemológicos sobre esa característica inevitable? Y ¿para qué queremos esos controles? ¿los queremos? La respuesta está lejos de ser unívoca. 
El debate sobre la justicia, la verdad y las políticas de derechos humanos

En el contexto del nuevo ciclo de procesos judiciales por delitos de lesa humanidad, que se inició en la década de los 2000 en la Argentina, y de una fuerte discusión sobre la manera en que las gestiones kirchneristas pusieron el tema de los derechos humanos en el centro de sus políticas, en los últimos años surgieron nuevos debates que atravesaron profundamente al campo de las ciencias sociales vinculado al pasado reciente. En efecto, desde distintos círculos intelectuales y políticos surgieron una serie de planteos que pusieron en cuestión el objetivo de justicia como política central de reparación en el caso argentino, así como la calidad institucional de los procesos penales que se estaban Ilevando adelante y, asociado con ello, algunos reavivaron la discusión sobre un horizonte de reconciliación como cierre posible y deseable del pasado. A su vez, como ya se señaló, estos debates se dieron en el contexto del cierre del ciclo político kirchnerista y la llegada de una nueva alianza de la derecha al poder (en torno a 2015), lo cual habilitó la emergencia de nuevos discursos relativizadores y/o banalizantes sobre la dictadura y con amplia repercusión mediática entre algunos sectores partícipes del nuevo momento político. En ese clima de cambio de época hubo una multiplicidad de actores, posiciones y tópicos en discusión; así, además de los debates sobre la justicia y la verdad en los que concentramos el análisis que sigue, también surgieron voces que cuestionaban, por ejemplo, la cifra de treinta mil desaparecidos, los alcances del terrorismo de Estado o el valor de los derechos humanos como paradigma éticopolítico. $^{19}$

En ese contexto, el arco de cuestionamientos al proceso de justicia como política de derechos humanos provino, por un lado, de sectores de la derecha política, claramente asociados a los intereses dictatoriales en los años setenta, es decir, las jerarquías de la Iglesia Católica, un sector de la prensa, especialmente, el diario La Nación, algunas

\footnotetext{
${ }^{19}$ La discusión sobre el número de "treinta mil desaparecidos" tuvo amplia repercusión mediática y estuvo originada en declaraciones de funcionarios del gobierno de "Cambiemos" negando el número de "treinta mil". Sin duda, la determinación de la cifra exacta de desaparecidos está aún pendiente en la Argentina, pero las objeciones no apuntaban al problema cuantitativo strictu sensu sino a cuestionar el valor histórico-político de esa cifra y, por ende, la lucha política de los organismos de derechos humanos así como los alcances y el impacto de la represión en la Argentina (COLECTIVO DE HISTORIA RECIENTE, 2017 y "La memoria remite al pasado pero se conjuga en presente", BECARIOS DOCTORALES DEL CONICET, (BALE, 2017)).
} 
los juicios por crímenes de lesa humanidad como un acto de venganza, en un momento en que, además, los procesos judiciales comenzaban a involucrar responsabilidades civiles en la represión. A su vez, muchos de estos argumentos coincidían con otros que relativizaban la represión estatal, sosteniendo que sus alcances no habían sido tales o intentando poner en un mismo plano la violencia del estado y la violencia de las organizaciones armadas. ${ }^{21}$ Mientras tanto, algunos protagonistas de ese pasado, militantes o familiares de víctimas, se unieron al planteo de la reconciliación o diálogo, y en otra variante, a la necesidad de asumir las responsabilidades en relación con la "locura" de la violencia del pasado y la necesidad de saber perdonar. ${ }^{22}$

Desde otro lugar distinto, pero con efectos coincidentes, posiciones intelectuales asociadas a la izquierda y el progresismo y activos participantes de las discusiones académicas sobre historia reciente, comenzaron a plantear que la búsqueda de justicia en la Argentina había ido en detrimento de la obtención de verdad. Por ejemplo, que si se hubiera privilegiado la obtención de verdad ofreciendo una disminución de penas a los acusados a cambio de información, hoy sabríamos lo sucedido con los desaparecidos o los niños apropiados. Como corolario de ello también se señaló que las formas de esa escena judicial dificultaron la confrontación de los perpetradores con sus crímenes, y por tanto, la posibilidad de arrepentimiento, y eventualmente de alguna forma de perdón por parte de las víctimas (HILB, 2013 y 2014a). En relación con ello, varias voces sostienen que

\footnotetext{
${ }^{20}$ Entre otros, mesa redonda organizada por la Universidad Católica Argentina (UCA), "Una reflexión sobre los años setenta: de la lógica del enfrentamiento a la cultura del diálogo" (5/8/2015), y su cobertura por el diario La Nación, 6/8/2015 (http://www.lanacion.com.ar/1816631-en-la-uca-un-pedido-por-la-memoria-yla-reconciliacion); mesa redonda organizada por la Universidad de San Andrés "Derechos humanos y castigo: las discusiones pendientes" y su cobertura en La Nación, 20/5/2015 (http://www.lanacion.com.ar/1820609-cuestionan-el-procedimiento-de-los-juicios-por-lesa-humanidad); también Romero, 2014 y notas diversas del diario La Nación: “No más venganza" (23/11/2015, http://www.lanacion.com.ar/1847930-no-mas-venganza); "Reconciliación indultos y amnistías" (21/8/2015; http://www.lanacion.com.ar/1820882-reconciliacion-indultos-y-amnistias), “Más justicia militante" (13/8/2016; http://www.lanacion.com.ar/1927679-mas-justicia-militante).

${ }^{21}$ Por ejemplo, Romero, 2014, y editorial del diario La Nación, 23/11/2015, cit. Véanse respuestas a ello en Campos y Rot, 2015.

${ }^{22}$ El diálogo, con Héctor Leis y Graciela Fernández Meijide, film, 2014; también mesa redonda organizada por la UCA (cit. supra), con familiares de víctimas de la guerrilla y de la represión estatal.
} 
el modelo sudafricano de reconciliación y perdón -a partir de lo hecho por la Comisión de Verdad y Reconciliación (CNV) en ese país- habría sido más efectivo que el modelo argentino centrado en la justicia y la "judicialización del pasado", pues este pagó un "alto precio en verdad". Este punto del argumento, especialmente en Claudia Hilb, no sólo se refiere a los crímenes militares sino en especial a la "verdad" que implicaría reconocer las responsabilidades más amplias que contribuyeron al "advenimiento del Terror", empezando por aquellas de las organizaciones armadas de los años setenta (HILB, 2013, p. 104 y ss). Otro derivado de la crítica a la “judicialización” sostiene que los juicios llevados adelante en la Argentina en los años 2000 están atravesados por una serie de procedimientos arbitrarios, en diferente medida violatorios de las garantías de los acusados o irrespetuosos de las necesidades de las víctimas (HILB, 2013; 2014b; 2015; HILB, SALAZAR Y MARTÍN, 2014; MARTÍN, 2014; MARTÍN, 2016).

Estas posiciones fueron recibidas con intensas reacciones dentro del campo académico de la historia reciente que objetaron a través de notas periodísticas, textos de intervención política, eventos y trabajos científicos diversos aspectos de esos argumentos. ${ }^{23}$ Estas intervenciones, a su vez, también asumieron una posición fuerte y reactiva frente a la coyuntura política abierta por llegada del macrismo al poder en diciembre de 2015. En primer lugar, se cuestionó la dicotomía entre verdad y justicia planteada por estos intelectuales y sectores de poder, señalando que en la Argentina, las Fuerzas Armadas nunca estuvieron dispuestas a dar información y siempre se abroquelaron en la convicción ideológica de lo actuado. Por lo tanto, la vía judicial fue una opción resultante del equilibrio de fuerzas y la negativa militar a hablar. Esto permitiría suponer que difícilmente algunas concesiones en términos de reducción de penas hubieran aportado información efectiva (COLECTIVO DE HISTORIA RECIENTE, 2015; FELD Y SALVI, 2016; OBERTI y PITTALUGA, 2016; FRANCO, 2016 (b)). A su vez, también se

\footnotetext{
${ }^{23}$ El Colectivo de Historia Reciente, que reúne a la mayoría de los investigadores y centros de investigación del país sobre el tema de la dictadura, emitió dos declaraciones que recogieron cerca de dos mil firmas en pocas horas: "¿Historia y/o política? La verdadera democracia se construye con verdad y con justicia”, septiembre de 2015 y "Frente a la banalización del terrorismo de Estado y los derechos humanos", marzo 2017. También véase otras respuestas en Oberti y Pittaluga, 2016; Campos y Rot, 2015 y 2017, Becarios doctorales de Conicet, 2017. Asimismo, muchos de las respuestas fueron planteadas desde la propia investigación académica, por ejemplo, varios de los artículos del dossier coordinado por Feld y Salvi, 2016; Franco, en prensa (a).
} 
En segundo lugar, se discutió la comparación con el caso sudafricano y se puso en evidencia cómo las resoluciones particulares de cada país obedecieron a negociaciones y equilibrios de fuerzas coyunturales y locales y, por tanto, no se trata de la elección entre uno y otro modelo sino de la comprensión histórica de los caminos que llevaron a cada una de esas salidas. Asimismo, se discutió las limitaciones de la resolución sudafricana a través de la CVR mostrando que fue una "solución de compromiso" y que la amnistía a través del perdón tuvo consecuencias negativas en torno a satisfacer las demandas de las víctimas, cerrar el ciclo de violencia y contribuir a una real comprensión histórica del apartheid y de la violencia. Ello se debió, entre otras razones, a que los pedidos de amnistía ante la CVR fueron individuales y en su gran mayoría no implicaron arrepentimiento ni aportaron información relevante, así como tampoco permitieron reconstruir la dimensión de la violencia estatal. Por último, también se alumbró el hecho de que quienes se presentaron ante la Comisión fueron principalmente miembros de la oposición, especialmente del Congreso Nacional Africano y no de las fuerzas de seguridad vinculadas al apartheid, y que el trabajo de la CVR es muy poco conocido en ese país como para que haya tenido los efectos de reconciliación y reconstrucción social que se le atribuyen (FEIERSTEIN, 2014; PINEAU Y FLORES, 2016; OBERTI Y PITTALUGA, 2016).

Por último, en relación con los procesos judiciales actuales en la Argentina, las respuestas académicas tuvieron que ver con reafirmar la opción por la justicia y la importancia de la vía judicial como forma reparatoria para las víctimas, poniendo en evidencia algunos de los presupuestos subyacentes en las nuevas posturas contrarias, tal como muestran Oberti y Pittaluga (2016). En efecto, por un lado, muchos de aquellos planteos ${ }^{25}$, están situados en la construcción de un momento ideal en torno a los

\footnotetext{
${ }^{24}$ Un ejemplo privilegiado de este proceso y de la relación virtuosa entre justicia y verdad es el juicio en relación con la ESMA que investigó y probó por primera vez la existencia de los "vuelos de la muerte" (Página 12, 3/12/2017, https://www.pagina12.com.ar/80090-hubo-una-industrializacion-del-exterminio; FELD y FRANCO, 2017).

${ }^{25}$ No aquellos que son abiertamente favorables a la impunidad pero sí aquellos provenientes de un espectro intelectual considerado "progresista".
} 

más reciente, considerado un momento "partisano" y "faccioso" de los derechos humanos $\mathrm{y}$, por tanto, de una justicia también parcial o incluso vengativa -según los matices- asociada a la revisión que el kirchnerismo produjo de los años dictatoriales-. Como sostienen Oberti y Pittaluga (2016), uno de los temas fundamentales que subyace a esta discusión es el problema de la violencia revolucionaria y armada de los años setenta y cómo se entiende y qué lugar se le atribuye en el ciclo de violencia política. En definitiva, la demanda por una verdad más cabal, por “toda la verdad" que no lograrían alumbrar los juicios tiene que ver con ello, con la idea de que existen unas responsabilidades que la escena de una justicia parcial estaría obliterando.

Así, aunque cada grupo de posiciones incluye y encubre en su seno argumentos disimiles y no todos congruentes, un foco fundamental de la tensión tiene que ver con las lecturas que se hacen de lo que algunos denominan la experiencia revolucionaria y otros el fenómeno "terrorista” en los años setenta. En buena medida, hay una línea clara por la cual quienes cuestionan la "partidización” o "faccionalización” de los derechos humanos durante las gestiones kirchneristas objetan también cierta recuperación de la experiencia militante por parte de esas corrientes políticas y cuestionan la falta de un balance crítico de la experiencia armada en la Argentina. Desde allí, algunas voces objetan la falta de una "memoria justa" que ponga en evidencia los crímenes de las organizaciones armadas y la manera en que ellas contribuyeron al ciclo de violencia política (VEZZETTI, 2009) y la construcción de una “memoria oficial” en esa línea (CARNOVALE, 2015-2016); otros directamente reclaman un monumento que identifique y unifique por igual a todas las víctimas para construir una "cultura democrática" de cara al futuro (ROMERO, 2017). ${ }^{27}$

\footnotetext{
${ }^{26}$ Véase la entrevista a Roberto Gargarella y Hugo Vezzetti en Ferández Irusta, 2017, y de manera más general las posiciones sostenidas por la "Mesa de discusión sobre derechos humanos, democracia y sociedad".

${ }^{27}$ En este último grupo de posiciones algunos se hicieron eco de la intervención de Tzvan Todorov (2010) luego de una vista a la Argentina en la que reclamaba una historia que no silenciara el rol del "terrorismo revolucionario", una verdad más completa y formas de reencuentro entre víctimas y victimarios.
} 
Para concluir, a diferencia de los debates anteriores, estas discusiones están fuertemente ligadas a las políticas de Estado y a los ciclos políticos frente a los cuales los investigadores e intelectuales intervinieron. Ello nos permite introducir otro tema bien distinto pero ciertamente pendiente para el campo historiográfico de la historia reciente: ¿Cómo puede contribuir la producción académica en las batallas públicas desde su lugar específico? ¿Cómo hacerlo desde la intervención política en tanto investigadores y desde la propia producción profesional? Cuando los investigadores salen al debate político ¿tienen capacidad de ser escuchados? ¿Qué perdemos de nuestro "rigor profesional” para ser escuchados más ampliamente? ¿Qué hay en eso que perdemos tan importante de ser custodiado? ¿Cómo preservamos lo mejor de nuestra ética profesional y nuestra búsqueda de conocimiento riguroso honrando, al mismo tiempo, el compromiso ciudadano que nos moviliza?

\section{A modo de cierre (de lo que no tiene cierre)}

Estos debates y las preguntas que promueven están profundamente insertos en la coyuntura de las tensiones políticas argentinas de los últimos años. Al mismo tiempo, ponen en evidencia algunas cuestiones fundamentales del campo profesional de la historia reciente: la politicidad de esta historiografía, su carácter más presente que pasado, y la tensión entre las diferentes esferas de acción del investigador. Estas cuestiones son ciertas para cualquier historiografía pero en este campo son claramente más acuciantes.

La politicidad de la historia reciente académica no es un problema en sí mismo, es sólo una característica distintiva del campo. Se torna un problema cuando no es acompañada por una reflexión sobre las formas de interacción, distinción y autonomía entre las distintas esferas y la necesidad de construir espacios de autonomía relativa cuestión que es evidente para los dos primeros debates analizados aquí-.

En efecto, este es un punto que la historiografía de la historia reciente no ha abordado ni pensado como parte de las exigencias y las demandas éticas y políticas del campo. En la Argentina, hemos usado mucha energía para construir la legitimidad 

intersubjetivamente lo que es historiografía profesional. Sin embargo, luego de ese esfuerzo de validación profesional, una vez que el campo está consolidado y goza de cierta autoridad reconocida afuera del mundo académico, nos falta avanzar en pensar cómo negociamos en cada situación la interacción entre estos ámbitos diferenciados y sus luchas específicas. ${ }^{28}$ Porque el investigador puede participar en ellas o no, pero la existencia misma de esas otras esferas es parte del motor de existencia de nuestra propia esfera dedicada al conocimiento.

Por tomar un ejemplo aquí abordado, el de los conceptos, es necesario discriminar distintos usos posibles: mientras en la esfera pública los conceptos construyen sentidos políticos y sociales y tienen menor necesidad de precisión y adecuación, en la esfera académica -o incluso la jurídica- los conceptos tienen otras exigencias (SCATIZZA, 2016). ¿Qué nos interesa: comprender adecuadamente un proceso o contribuir a la batalla judicial o política? ¿Qué hacemos cuando las operaciones cognitivas de las ciencias sociales, por ejemplo la búsqueda de conceptos adecuados para describir fenómenos y realidades, son percibidas como amenazas a las batallas públicas por el pasado que nosotros mismos podemos compartir como académicos y ciudadanos? ¿Cómo, cuándo o por qué adecuaríamos nuestro discurso y/o lo pondríamos al servicio de batallas éticopolíticas? ¿Qué sucede cuando eso entra en tensión con la ética profesional ligada a la construcción de conocimiento? ¿Existe tal distinción posible en el ámbito de la historia reciente o la politicidad del campo oblitera cualquier distinción similar?

El último campo de tensiones analizado en torno a la justicia y las políticas de derechos humanos desde el punto de vista de la historiografía de la historia reciente ha puesto en evidencia otra cuestión, casi inversa: la imposibilidad de sustraerse a los compromisos ciudadanos y políticos que mueven a esta historiografía y dejan a la vista, una vez más, parte de los motores fundamentales de este campo. Sin embargo, tal vez la diferencia interesante es que en los últimos años las intervenciones políticas y colectivas

\footnotetext{
${ }^{28}$ Entre las pocas excepciones de quienes han reflexionado sobre el tema, Scatizza, 2016.
} 
de buena parte de quienes participamos del campo de la historia reciente se han fundado en nuestros saberes profesionales. No desde la autoridad de una posición científica que se autolegitima por esa condición, sino desde la construcción y acumulación de conocimiento profesional que nos permite disputar y discutir en el espacio público. Dicho esto, seamos claros: nuestros saberes no son suficientes para ganar estas batallas porque esas batallas dependen de dimensiones y coyunturas que exceden infinitamente al campo académico-, pero al menos también son la prueba de que en la Argentina el campo de la historia reciente es ya un espacio ampliamente profesionalizado, que ha logrado articular investigación rigurosa y compromiso ético-político. Sin embargo, al mismo tiempo, aún debe disputar y construir otros relatos públicos desde sus propios saberes y reglas. En definitiva, nos falta reflexionar sobre las articulaciones posibles, deseables y no deseables entre estas diversas esferas de nuestro quehacer, no para encontrar una respuesta unívoca sobre cómo vincular esos ámbitos, sino para ser conscientes de que permanentemente estamos haciendo elecciones al respecto. $Y$ que nuestras respuestas y decisiones pueden variar según las coyunturas, los espacios y los temas, pero no deberíamos dejar de interrogarnos sobre ello una y otra vez.

\section{Referencias}

AAVV. Sobre la responsabilidad: no matar. Córdoba: El Cíclope Ediciones-La IntemperieUniversidad Nacional de Córdoba. 2007 y 2010. 2 vol.

AAVV. Responsabilidad empresarial en delitos de lesa humanidad: Tomo I represión a trabajadores durante el terrorismo de Estado. Buenos Aires: Ministerio de Justicia y Derechos Humanos de la Nación, 2015.

AARÃO REIS, Daniel. Ditadura e democracia no Brasil: do golpe de 1964 à constituição de 1988. Rio de Janeiro: Zahar, 2014.

AGUILA, Gabriela. Problemas y debates en torno a la conceptualización de la dictadura y la represión. In: JORNADAS DE TRABAJO SOBRE HISTORIA RECIENTE, VII, La plata, 2014. Mesas de debate. La Plata: Universidad Nacional de La Plata, La Plata, 2016, p. 69-90. 
Disponible: <http://www.libros.fahce.unlp.edu.ar/index.php/libros/catalog/book/65>. Acesso em: 18/11/2016.

ALEGRE, Marcelo. De la ESMA al INDEC: la justicia frente al poder. En: BOHOSLAVSKY, Juan Pablo, (Ed.). ¿Ud. también, doctor? Buenos Aires: Siglo XXI, 2015.

ALONSO, Luciano. La definición de las ofensas en el movimiento por los derechos humanos en la Argentina y la calificación de genocidio, Contenciosa, Año 1, n. 1, jul./dez., 2013.

BALE, Cinthia et al. Declaración: la memoria remite al pasado pero se conjuga en presente. Perfil: Periodismo puro. 28 de maio de 2017. Disponible: $<$ http://www.perfil.com/elobservador/la-memoria-remite-al-pasado-pero-se-conjuga-enpresente.phtml>. Acesso em: 12/08/2017.

BÉDARIDA, François. L'histoire du temps présent. Sciences Humaines, n.18, sep./oct., 1997.

BOHOSLAVSKY, Juan Pablo (Ed.) ¿Ud. también, doctor? Buenos Aires: Siglo XXI, 2015.

BORRELLI, Marcelo. Por una dictadura desarrollista: Clarín frente a los años de Videla y Martínez de Hoz, 1976-1981. Buenos Aires: Prometeo, 2016.

CAMPOS, Esteban; ROT, Gabriel. Neonegacionismo: sobre guerrilla, desaparecidos y devaluación del pasado. La izquierda diario, 10/3/2017. Disponible:

<https://www.laizquierdadiario.com/Neonegacionismo-sobre-guerrilla-desaparecidos-ydevaluacion-del-pasado>. Acesso em:

CAMPOS, Esteban; ROT, Gabriel. Sobre el pedido de reconciliación de La Nación. Clarín y Perfil. Pajarorojo. 21/9/2015. Disponible: <http://pajarorojo.com.ar/?p=18357>. Acesso em: 24/09/2017.

CANELO, Paula. El proceso en su laberinto. Buenos Aires: Prometeo, 2008.

CANELO, Paula. La política secreta de la última dictadura argentina. Buenos Aires: Edhasa, 2016.

CARNOVALE, Vera. Instantáneas: los juicios al mal. verdad, justicia y derechos humanos en Argentina. Políticas de la Memoria: Anuario de Investigación del CEDINCI, n. 16., 20152016.

COLECTIVO DE HISTORIA RECIENTE. ¿Historia y / o política? La verdadera democracia se construye con verdad y con justicia. Buenos Aires, sept, 2015. Disponible: <https://historiarecienteargentina.wordpress.com/2015/09/28/la-democracia-se-construyecon-verdad-y-con-justicia-manifiesto-de-los-investigadores-en-historia-reciente/)>. Acesso em: $7 / 6 / 2017$. 
COLECTIVO DE HISTORIA RECIENTE. Frente a la banalización del terrorismo de Estado y los derechos humanos. 2017. Disponible:

https://docs.google.com/forms/d/e/1FAIpQLSeAr5d6o6gQBWUyeUg7aBvEq6ph-

IskIEEawvwXRaXms2NmGg/viewform?c=0\&w=1 acesso em: 11/09/2017

COPELLO, David. L'usage politique des droits de l'Homme : trajectoires militantes et répertoires discursifs des nouvelles gauches argentines (1971-2012). 2017. Tesis (Doctorado) - Sciences Po, París, 2017.

CRENZEL, Emilio. Hacia una historia de la memoria de la violencia política y los desaparecidos en la Argentina. In: MONTAÑO, Eugenia Allier ; CRENZEL, Emilio. Las luchas por la memoria en América Latina. México DF: Bonilla Artigas-UNAM, 2015, p. 35-62.

CUETO RÚA, Santiago. Ampliar el círculo de los que recuerdan: la inscripción de la Comisión Provincial por la Memoria en el campo de los derechos humanos y la memoria (1999-2009). 2016. Tesis (Doctorado) - Universidad Nacional de La Plata, La Plata, 2016.

DEMASI, Carlos, et al. La dictadura cívico-militar: Uruguay 1973-1985. Montevideo: Ediciones de la Banda Oriental, 2010.

DUHALDE, Eduardo L. El estado terrorista argentino: quince años después, una mirada crítica. Buenos Aires: Eudeba, 1999.

FEIERSTEIN, Daniel. El genocidio como práctica social. Buenos Aires: FCE, 2007.

FEIERSTEIN, Daniel. Sobre conceptos, memorias e identidades: guerra, genocidio y/o terrorismo de Estado en Argentina. Política y Sociedad, v. 48 n. 3, p.571-586, 2011.

FEIERSTEIN, Daniel. ¿Sudáfrica o Argentina? Página 12, dez. 2014. Disponible: <https://www.pagina12.com.ar/diario/elpais/1-243023-2014-03-30.html>. Acesso em: 7/09/2017.

FELD, Claudia; FRANCO, Marina. Los vuelos de la muerte. El legado de la justicia. Página 12, nov., 2017. Disponible: <https://www.pagina12.com.ar/79048-los-vuelos-de-la-muerteel-legado-de-la-justicia>. Acesso em: 12/11/2017.

FELD, Claudia; SALVI, Valentina. Presentación. Cuando los perpetradores hablan. Dilemas y tensiones en torno a una voz controvertida. Rubrica Contemporanea, v. 5, n.9, 2016. Disponible: <http://revistes.uab.cat/rubrica>. Acesso em: 4/09/2017.

FELD, Claudia; SALVI, Valentina. ¿Por qué hablarían los represores? Página 12, ago., 2015. Disponible: <https://www.pagina12.com.ar/diario/elpais/1-280457-2015-08-29.html>.

Acesso em: 23/09/2017.

FICO, Carlos. Ditadura militar brasileira: aproximações teóricas e historiográficas. Revista Tempo e Argumento, Florianópolis, v. 9, n. 20, p. 5-74, jan./abr., 2017.

FRANCO, Marina. La noción de dictadura cívico-militar. In: JORNADAS DE TRABAJO SOBRE 
HISTORIA RECIENTE, VII, La plata, 2014. Mesas de debate, La Plata: Universidad Nacional de La Plata, 2016a, p. 69-90. Disponible:

<http://www.libros.fahce.unlp.edu.ar/index.php/libros/catalog/book/65>. Acesso em: 23/09/2017.

FRANCO, Marina. La verdad y la justicia en la transición argentina. Review de libros, v.II,n. 10, nov./dic.; 2016b.

FRANCO, Marina. A título de conclusão: a história das ditaduras recentes do Cone Sul como desafío epistemológico. In: RAMÍREZ Hernán; FRANCO Marina (Eds.). Ditaduras no Cone Sul da América Latina. En prensa (a).

FRANCO, Marina. El final del silencio. Dictadura, sociedad y derechos humanos. Buenos Aires, Fondo de Cultura Económica, en prensa (b).

FRANCO, Marina; LVOVICH, Daniel. La historia reciente, apuntes sobre un campo en expansión, Boletín del Instituto de Historia Argentina y Americana Dr. Emilio Ravignani, n. 46, sep., 2017.

GERLACH, Christian. Extremely Violent SocietiesCambridge University Press. Cambridge, 2010.

HILB, Claudia. La virtud de la justicia y su precio en verdad. Una reflexión sobre los juicios a las Juntas en la Argentina, a la luz de la Comisión de la verdad y la Reconciliación en Sudáfrica. In: HILB Claudia. Usos del pasado. Buenos Aires: Siglo XXI, 2013.

HILB, Claudia. Justicia, reconciliación y perdón: cómo fundar una comunidad después del crimen. In: HILB Claudia; SALAZAR Philippe Joseph MARTÍN Lucas (Eds.). Lesa

humanidad: Argentina y Sudáfrica, reflexiones después mal. Buenos Aires: Katz, 2014ª .

HILB, Claudia. Reflexiones sobre el caso Milani. Lucha Armada, n.10, 2014b.

HILB, Claudia. De Eichmann en Jerusalén a los “juicios” en Argentina. Reflexiones situadas. Estudios sociales, n.48, p. 91-104, 2015.

HILB, Claudia; SALAZAR, Philippe Joseph; MARTIN, Lucas (Eds.). Lesa humanidad: Argentina y Sudáfrica, reflexiones después mal. Buenos Aires: Katz, 2014.

ITURRALDE, Micaela. El terrorismo de estado en noticias: Clarín ante la cuestión de los derechos humanos (1975-1985). 2016. Tesis (Doctorado en Ciencias Sociales), Universidad Federal de General Sarmiento, 2016.

LLORET, Rodrigo. Frente a la banalización del terrorismo de Estado y los derechos humanos. Colectivo de Historia Reciente .Diario Perfil, 04 de abr. de 2017. Disponible: <http://www.perfil.com/columnistas/la-banalizacion-del-terrorismo-de-estado-y-losderechos-humanos.phtml>. 
LVOVICH, Daniel; BISQUERT, Jacquelina. La cambiante memoria de la dictadura. Buenos Aires: Biblioteca Nacional/UNGS, 2008.

MARTINS FILHO, João. Adieu à la dictature militaire? Brésil(s), n. 5, p. 17-32, 2014.

MARTÍN, Lucas. 1985, 1995 y 2005: Justicia, derechos humanos y lazo político a treinta años. In: CHERESKY I. et al. Pensar la política hoy: treinta años de democracia. Buenos Aires: Biblos, 2014.

MARTíN, Lucas. La víctima en el centro. Review de libros, año II, n. 10, nov./dic., 2016.

MONTERO, Ana Soledad. ¡Y al final un día volvimos! Los usos de la memoria en el discurso kirchnerista (2003-2007). Buenos Aires: Prometeo, 2011.

MONTERO, Ana Soledad. El objeto discursivo ‘dictadura cívico-militar' en la Argentina reciente: narrativas históricas y sentidos contemporáneos. Crítica Contemporánea, diciembre 2016.

MUDROVCIC, María Inés. Alcances y límites de perspectivas psicoanalíticas en historia. Diánoia, v. XCVIII, n. 50, mayo, 2003.

NÁPOLI, Bruno; PEROSINO, Celeste; BOSISIO, Walter. La dictadura del capital financiero. Buenos Aires: Peña Lillo-Ediciones Continente, 2014.

OBERTI, Alejandra; PITTALUGA, Roberto. Apuntes para una discusión sobre la memoria y la política de los años 60/70 a partir de algunas intervenciones recientes. Sociohistórica, n.38, 2016.

ORTIZ DE ZARATE, Verónica Valdivia. El golpe después del golpe. Santiago:LOM, 2003.

PINEAU, Marisa; FLORES, Celina. ¿Arrepentimiento? ¿Justificación? ¿Voces perdidas? Luces y sombras de los testimonios de los perpetradores en la Sudáfrica post-apartheid. Rubrica Contemporanea, v. 5, n. 9, 2016. Disponible: <http://revistes.uab.cat/rubrica>. Acesso em: $4 / 10 / 2017$.

PITTALUGA, Roberto. ¿Qué queremos que sea la historia reciente? In: JORNADAS DE TRABAJO SOBRE HISTORIA RECIENTE, VII, La plata, 2014. Mesas de debate. La Plata: Universidad Nacional de La Plata, 2016, p. 114-120. Disponible:

<http://www.libros.fahce.unlp.edu.ar/index.php/libros/catalog/book/65>. Acesso em: $18 / 09 / 2017$.

PITTALUGA, Roberto. El pasado reciente argentino. Interrogaciones en torno a dos problemáticas. In: BOHOSLAVSKY, Ernestoet al. Problemas de Historia Reciente del Cono Sur. Buenos Aires: Prometeo, v. 1, p. 23-36, 2010.

RAFECAS, Daniel. La reapertura de los procesos judiciales por crímenes contra la humanidad. In: ANDREOZZI, Gabriele (Coord.). Juicios por crímenes de lesa humanidad en Argentina. Buenos Aires: Cara y Ceca, 2011, p. 155-176. 
ROMERO, Luis Alberto.Derechos humanos de la justicia a la venganza. La Nación, mar., 2014. Disponible: <http://www.lanacion.com.ar/1674836-derechos-humanos-de-la-justiciaa-la-venganza)>. Acesso em: 7/08/2017.

ROMERO, Luis Alberto. El kirchnerismo fue un grupo que se apropió del Estado, dijo el historiador Luis Alberto Romero. La Nación, jul.,2017. Disponible:

<http://www.lanacion.com.ar/2041624-el-kirchnerismo-fue-un-grupo-que-se-apropio-delestado-dijo-el-historiador-luis-alberto-romero>. Acesso em: 7/08/2017.

ROZANSKI, Carlos. Delitos de lesa humanidad y genocidio, origen y sentido de las prohibiciones". In: ANDREOZZI, Gabriele (coord.). Juicios por crímenes de lesa humanidad en Argentina. Buenos Aires: Cara y Ceca, 2011, p. 177-198.

SCATIZZA, Pablo. Un Comahue violento. Buenos Aires: Prometeo, 2016.

SIGAL, Silvia. La polémica sobre el genocidio, Puentes, año.2, n. 5, 2001.

TODOROV, Tzvan. Un viaje a Argentina. El País, dez.2010. Disponible: https://elpais.com/diario/2010/12/07/opinion/1291676411_850215.html). Acesso em: 7/10/2017.

VERBITSKY, Horacio; BOHOSLAVSKY, Juan Pablo (eds.). Cuentas pendientes. Buenos Aires: Siglo XXI, 2013.

VEZZETTI, Hugo. Pasado y presente. Buenos Aires: Siglo XXI, 2002.

VEZZETTI, Hugo. Verdad jurídica y verdad histórica. Condiciones, usos y límites de la figura del "genocidio". In: HILB ,Claudia; SALAZAR, Philippe-Joseph; MARTÍN, Lucas (Eds.), Lesa humanidad Argentina y Sudáfrica: reflexiones después del Mal. Buenos Aires: Katz, 2014.

VEZZETTI, Hugo. Sobre la violencia revolucionaria. Buenos Aires: Siglo XXI, 2009. 
Recebido em 15/12/2017 Aprovado em 28/02/2018

Universidade do Estado de Santa Catarina - UDESC Programa de Pós-Graduação em História - PPGH

Revista Tempo e Argumento Volume 10 - Número 23 - Ano 2018 tempoeargumento@gmail.com 